\title{
An Approaching Motor Boat Induces Stress-Related Behaviors in Proboscis Monkeys (Nasalis larvatus) Living in a Riparian Area
}

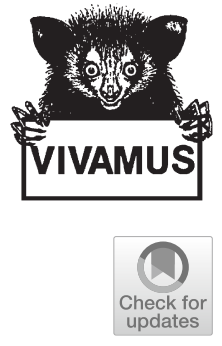

\author{
Marina Davila-Ross ${ }^{1}$ (D) Helen Pople ${ }^{1} \cdot$ Violet Gibson $^{1}$ (D) \\ Senthilvel K. S. S. Nathan ${ }^{2}$ Benoit Goossens $s^{2,3,4}$ - Danica J. Stark ${ }^{3,4,5}$ (D)
}

Received: 9 March 2021 / Accepted: 11 January 2022 /Published online: 25 February 2022

(c) The Author(s) 2022

\begin{abstract}
Primate ecotourism is a fast-growing tourism sector that may have a negative effect on wildlife. In riparian areas, tourists can conveniently reach primates via motor boats, but no study has directly examined whether such boats cause stress in primates. Our goal was to test whether the approach of a motor boat induces stressrelated and other behaviors in proboscis monkeys (Nasalis larvatus), an Endangered species. We studied six one-male, multifemale groups living in a remote riparian area in Sabah, Malaysia, and conducted an experiment by approaching the monkeys in a motor boat by using three conditions with different speeds and travel distances (fast-close, slow-close, and slow-far conditions; 7-8 subjects per condition). For each condition, we compared stress-related behaviors before the boat approach with after the boat started approaching. Feeding, allogrooming and aggression were similarly examined, respectively. We also observed the monkeys' behaviors at other times to examine age-sex classes differences in vigilance, social proximity, allogrooming, aggression and play (87 subjects). In the experiment, subjects displayed stressrelated behaviors for longer in the fast-close and slow-close conditions once the boat started approaching than before the boat approach. The subjects also reduced feeding in the fast-close condition after the boat started approaching. In our observational study, males were more vigilant than females-a behavior that is likely to relate to male-male competition and group protection. This study provides evidence that even a single motor boat moving slowly, with humans behaving calmly, may negatively affect primate behavior and induce stress - an impact that is likely to be larger with tourist boats. Our study also shows that using conditions comparable to the slow-far condition (speed of $3.6 \mathrm{~km} / \mathrm{hr}$; no closer than $60 \mathrm{~m}$ ), where no impact
\end{abstract}

Marina Davila-Ross and Helen Pople contributed equally to this work.

Handling Editor: Joanna Setchell.

Extended author information available on the last page of the article 
was observed, may help with to develop guidelines for primate tourism in riparian areas. Future research that examines the impact of boats on other primates is needed.

Keywords Asian colobines $\cdot$ Vigilance $\cdot$ Motor boats $\cdot$ Human effect $\cdot$ Ecotourism

\section{Introduction}

Due to anthropogenic changes to the environment, humans will most likely continue to have increasing access to wild populations of nonhuman primates (from here on primates) and other wildlife, causing further challenges to their existence (Fuentes \& Hockings, 2010; Goossens et al., 2003; Lee, 2010; McKinney et al., 2015). Partly resulting from such changes, ecotourism is one of the fastest-growing tourism sectors (Fan \& Xiang, 2013; McKinney, 2018; McKinney et al., 2015; Timm et al., 2009). Ecotourists, who regularly get close to wildlife, can increase disease transmission (Chapman et al., 2005; Hsu et al., 2009; Muehlenbein et al., 2010; O'Leary \& Fa, 1993) and cortisol levels (Behie et al., 2010; Maréchal et al., 2011; Muehlenbein et al., 2012) in primate populations, suggesting a damaging effect of ecotourism on wildlife (McKinney, 2018; McKinney et al., 2015).

Behavioral research shows that wild and captive primates may display stressrelated behaviors, such as self-scratching, vigilance, and avoidance, when they are exposed to groups of ecotourists or zoo visitors (Hayward \& Hayward, 2009; Hosey, 2000, 2005; Maréchal et al., 2011; Mitchell et al., 1992; Treves \& Brandon, 2005). Frequent visits by such groups and their behaviors, which often involve an unusually high level of noise, increase aggression in primates (Mitchell et al., 1991) and decrease their affiliative interactions with conspecifics, such as allogrooming and social play (Chamove et al., 1988; de la Torre et al., 2000; O'Leary \& Fa, 1993), as well as their foraging behaviors (Birke, 2002; de la Torre et al., 2000; Grossberg et al., 2003). A recent study of Japanese macaques (Macaca fuscata) showed that large crowds of zoo visitors may even affect their cognitive abilities (Huskisson et al., 2021).

The riparian area is an important habitat that has become increasingly popular to primate ecotourism, because it enables tourists to conveniently reach primates via motor boats (Benchimol \& Venticinque, 2014; de la Torre et al., 2000; Goossens et al., 2003; Lhota et al., 2019; McKinney et al., 2015; Serio-Silva, 2006; Vanlangendonck et al., 2015). Many of these boats, each having the capacity to carry multiple tourists, quickly and loudly approach the primates in these habitats, at times reaching the river banks just a few meters away from the wildlife (Leasor \& Macgregor, 2014; Sha et al., 2008). The primates are, in general, more exposed to the tourists at the river than deeper in the forest. Because noise alone may negatively affect wildlife (Shannon et al., 2016) and because motor boats are large, artificial, and fastmoving, these loud boats are likely to be threatening for primates and could lead to stress.

Most studies of the potential impact of boats on wildlife involve sea mammals and birds (Christiansen et al., 2010; Haysmith \& Hunt, 1995), and less research 
about this topic has been conducted on primates. Studies of sea mammals and birds have shown that moving boats can change the behaviors of wildlife in a negative way, for instance by inducing stress-related behaviors, including fleeing (Arcangeli et al., 2009; Stensland \& Berggren, 2007) and aggression (Constantine, 1999), and by interrupting foraging (Karczmarski et al., 1997; Mattson et al., 2005). The speed and distance of boats modifies sea mammal travel directions (Baş et al., 2017). In primates, proboscis monkeys (Nasalis larvatus) in a popular tourist area in Malaysia showed more agonistic behaviors when four tourist boats were present than when no boats were present (Leasor \& Macgregor, 2014). Furthermore, fecal testosterone levels were unusually high in male golden-mantled howler monkeys (Alouatta palliata palliata) and ornate spider monkeys (Ateles geoffroyi ornatus), in an area in Northeastern Costa Rica where 80 or more tourist motor boats visited these primates each day (Vanlangendonck et al., 2015). Wild pygmy marmosets played socially less and lived higher up in the trees in an area exposed to unusually high trourism pressure than in areas without such exposure (de la Torre et al., 2000).

Proboscis monkeys are particularly interesting to study regarding the impact of a motor boat on primates and to what extent it may induce stress-related behaviors. They often are subject to tourism in riparian areas because of their unusual appearance and because they are readily viewable from boats along the river. Proboscis monkeys are Endangered primates that are highly dependent on the riparian tropical forest of Borneo (Agoramoorthy et al., 2004; Bigoni et al., 2003; Lovett \& Marshall, 2006; Meijaard \& Nijman, 2000). Due to their specialized folivorous digestive system, they often feed in the trees along river banks (Agoramoorthy et al., 2004; Atmoko et al., 2020; Matsuda, Abram, et al., 2020a; Matsuda et al., 2009a; Yeager, 1989). They also sleep in the riparian forest, most likely for safety and uninterrupted views of predators (Salter et al., 1985; Thiry et al., 2016; Yeager, 1989).

Proboscis monkeys live in one-male, multifemale groups, and the sexes are likely to differ in their behaviors, especially behaviors associated with protecting the group. In one-male, multifemale groups, male vigilance may help in responding to predators and to males of other groups, with whom they compete for females (Baldellou \& Henzi, 1992; Gould et al., 1997; Rose \& Fedigan, 1995). In such groups, males and females differ in the resources they compete for (Grueter et al., 2012; Isbell \& Young 2002; Kirkpatrick et al., 1998), consistent with Darwin's (1871) sexual selection theory. Males show more aggressive encounters than females (Cheney \& Seyfarth, 1977; Kirkpatrick et al., 1998; Kitchen \& Beehner, 2007; cf. Sackett et al., 1975; Sjahfirdi \& Noviandini, 2021). In contrast to the males, females show more behaviors that promote social bonding, such as allogrooming, and they are close to other group members (Arnold \& Whiten, 2003; Wittig et al., 2008) even under harsh environmental conditions (Alberts et al., 2005).

Proboscis monkeys spend a large proportion of their day resting (22-76.5\%) and feeding (10-19.5\%), and a substantial part of their time (5-27.8\%) in vigilance and other stress-related behaviors (Boonratana, 1993, 2000; Leasor \& Macgregor, 2014; Matsuda et al., 2009a). The large range in vigilance across these studies could be explained by the varying presence of humans, including tourists and researchers (Boonratana, 1993; Leasor \& Macgregor, 2014; Matsuda et al., 2009a). Grooming (0.1-6.1\%) and aggression (0.3-0.8\%) are less common (Boonratana, 1993; Leasor 
\& Macgregor, 2014; Matsuda et al., 2009a; Yeager, 1990, 1991). To our knowledge, only one study directly compared male and female proboscis monkey behaviors. It revealed that an alpha male spent less time grooming than the females, and he also tried to rescue group members twice when they were attacked by a Sunda clouded leopard (Neofelis nebulosa) (Matsuda et al., 2008, 2009a, 2009b). Notably, this study focused on a single group (with 1 alpha male), so further studies are required to replicate and extend these findings (Rawlings et al., 2014).

We studied six groups of proboscis monkeys in a remote riparian area of the Kinabatangan River at the Lower Kinabatangan Wildlife Sanctuary (LKWS), Sabah, Malaysian Borneo. LKWS is estimated to have 2,000-3,000 proboscis monkeys (Matsuda, Stark, et al., 2020b; Stark et al., 2012). Our main purpose was to examine how the approach of a motor boat affects proboscis monkey behaviors. We conducted an experiment to test the hypothesis that an approaching boat may induce stress in proboscis monkeys. Specifically, we predicted that the approaching boat would lead to an increase in stress-related behaviors as well as aggression and a decrease in feeding as well as allogrooming, especially if the approach is fast and, consequently, loud or longer. In addition, we explored the behaviors of the proboscis monkey groups when they were in the riparian area (mornings and evenings), comparing hereby age-sex classes.

\section{Methods}

\section{Subjects and Study Site}

We studied proboscis monkeys along approximately $25 \mathrm{~km}$ of the Kinabatangan River (between $5^{\circ} 24^{\prime} 37.1^{\prime \prime} \mathrm{N} 117^{\circ} 58^{\prime} 48.6^{\prime \prime} \mathrm{E}$ and $5^{\circ} 25^{\prime} 00.9^{\prime \prime} \mathrm{N} 118^{\circ} 06^{\prime} 03.9^{\prime \prime E}$ ) in LKWS. This area of the forest is made up of lowland dry forest and seasonally flooded forest formed as part of a floodplain and is surrounded by oil palm plantations. The proboscis monkeys are regularly found sleeping and feeding in the trees along the river bank. They often travel inland during the day, leaving their sleeping sites at around 6:30 am and returning to the river bank at around 5:00 pm. We rarely observed proboscis monkeys on the ground along the river bank, except when juveniles were playing. The section of the river where we conducted the study had little boat traffic with virtually no tourism and few fishing boats.

We studied six one-male multifemale groups. We estimated group sizes as 10 to 30 members based on previous visits where we counted the individuals. Each group included one adult male, multiple adult and subadult females, juveniles, and infants. Three groups each had one GPS-collared group member (2 adult females: e-obs UHF 1C-Light: e-obs, Grünwald, Germany; 1 alpha male: Lotek Biotrack GSM Wildcell SD: Biotrack Ltd, Wareham, United Kingdom). GPS-collaring took place before this study for research on proboscis monkey ranging behavior (Stark et al., 2017). Of the remaining three groups, two were on the same side of the river, but 6.7-km apart, and the third group was on the opposite side of the river. Although proboscis monkeys can swim, we did not see them crossing the river during this 
study, likely due to the high number of crocodiles (Crocodylus porosus) in the area. The study groups were not habituated to humans.

For the boat experiment, subjects consisted of 9 alpha males and 14 adult females; none of these tested individuals were collared. Our observational study included 87 subjects: 31 adult females (including the 2 GPS-collared), 5 alpha males (1 GPScollared), 20 subadult females, 19 juveniles, and 12 infants.

We based age-sex class distinctions on physical features (Bennett \& Sebastian, 1988). Males have enlarged protruding noses compared with females and are twice as heavy as females (Matsuda et al., 2020b). Adult females are larger than subadult females, who are yet to develop a full body size, and juveniles are larger than infants, who have dark skin on their faces and are still dependent on their mothers.

In both studies, if we could not identify subjects beyond their age-sex class, we categorized them by age-sex class (e.g., unidentified adult female). These 16 "unidentified" subjects most likely represent multiple individuals, so the actual number of individuals studied is higher than 87 . We used this conservative approach to avoid pseudoreplication.

\section{Ethical Note}

This study was reviewed and approved by The University of Portsmouth Animal Welfare and Ethical Review Board, the Sabah Biodiversity Centre and the Sabah Wildlife Department. It adhered to the legal requirements of Sabah, Malaysia and the American Society of Primatologists Principles for the Ethical Treatment of Primates. The authors declare that they have no conflict of interest. In the GPS-collaring that Stark et al. (2017) performed, animal handling took place according to Sabah Wildlife Department's Standard Operation Procedures on Animal Capture, Anaesthesia and Welfare. A veterinarian specialized in wildlife capture and anesthesia performed the darting, used preventative measures to assist recovery from anesthesia, and monitored the animals throughout the procedure. The authors declare that they have no conflict of interest.

Data Availability Data are available from the corresponding author on reasonable request.

\section{Data Collection}

We video-recorded proboscis monkey behaviors in February to July 2015, which is a generally dry season compared with most other months. We made recordings from a boat using a JVC Everio GZ-MG750BEK camcorder with 45x dynamic zoom (Konica Minolta, Tokyo, Japan). We used focal animal sampling (Altmann, 1974), capturing the subjects and all conspecifics within $3 \mathrm{~m}$ of the subject. We started recording when the subjects showed no aggression or stress-related behaviors (i.e., direct gaze toward the boat and open-mouth facial displays), which may have been induced by our arrival in the boat, for more than 15 seconds. To avoid any potential impact on the monkeys, the driver 
moved the boat slowly when arriving at the recording site (i.e., before the recording), switched the engine off as soon as the boat reached the site and was not moving, and moved the boat slowly again when leaving the site (i.e., after the recording).

We estimated the river width as 40-140 $\mathrm{m}$ at recording sites (based on measurements obtained for about a third of the recordings; measured with Garmin eTrex 10 unit and Garmin BaseCamp: Garmin Ltd. Schaffhausen, Switzerland). For the experiment, we tested subjects when the river width was an estimated $100 \mathrm{~m}$ or wider. For the observational study, we video-recorded the subjects from the opposite bank of the river.

Our experiment included three conditions to test the impact of an approaching boat on the subjects. We chose conditions that were comparable in travel distance and speed and to avoid causing the primates to flee. These conditions were approach $40 \mathrm{~m}$ in $10 \mathrm{~s}$, at a speed of $14.4 \mathrm{~km} / \mathrm{hr}$ (fast-close condition, 5 females and 3 males tested), approach $40 \mathrm{~m}$ in $40 \mathrm{~s}$ at a speed of $3.6 \mathrm{~km} / \mathrm{hr}$ (slow-close condition, 5 females and 3 males), and approach $20 \mathrm{~m}$ in $20 \mathrm{~s}$, at a speed of $3.6 \mathrm{~km} / \mathrm{hr}$ (slowfar condition, 4 females and 3 males). The slow-far condition had a missing female as we had difficulties seeing her while recording. To ensure the approach distance was accurate, we used a rope marked every $10 \mathrm{~m}$. We practiced at another location before the experiment to ensure consistency of speed. We made focal recordings for 3 minutes before the boat approached the subject and for 3 minutes once the boat started approaching the subject (throughout the boat approach and the remaining time afterwards). We tested the proboscis monkeys no more than once a week per group (to minimize habituation and potential stress) and between 4:00 p.m. and 5:45 p.m. (to give them time to find another sleeping site if they left the site due to the boat approaching, although this never happened during data collection).

For the observational study, each focal sample lasted 3 minutes. We obtained 219 samples ( 68 for adult females, 36 for alpha males, 56 for subadult females, 40 for juveniles, and 19 for infants). We collected a mean of 2.5 recordings per subject, with a minimum of one and a maximum of six recordings. We could not obtain usable data for the sixth alpha male in this study, because we observed his group only once and his sex/age class was listed at a later stage in our predetermined order of filming so that he was difficult to see when it was his turn. We collected data between 6:00 a.m. and 07:00 a.m. and between 4:30 p.m. and 6:15 p.m. on 39 days spread throughout the study (to minimize habituation and potential stress). For morning recordings, we arrived slowly in the dark before the proboscis monkeys seemed to have woken up, started recording when the sun came out, and stopped once the monkeys moved into the forest. For evening recordings, we arrived after the monkeys were at their sleeping sites and stopped recording when it got dark and monkeys were no longer visible.

One recordist collected all recordings. We ran the experiment and observed behavior only when there was no rain, because the proboscis monkeys tended to shelter unseen in the trees during rain and when tourists were absent. We decided the order in which to film each GPS-collared group in advance and varied this order each visit (for the experiment) or each week (for the observational study). If we could not find this group, we searched for the group nearest to them along the river. We located the GPS-collared groups with radio-tracking antennae, i.e., Telonics RA-23K VHF (Telonics inc, Arizona, USA) and a Yagi-Uda UHF antenna. We also decided the order in which we filmed each sex/age class in advance and 
varied this order each visit. If more than one potential subject of the same age-sex class was present, we videoed the most clearly observable one (both face and body easily viewable). For the experiment, we selected an alpha male or an adult female that was not sitting next to other individuals, whenever possible, to reduce potential effects of these individuals on the subject's behaviors. For the observational study, we prioritized data collection for all adults and subadults in the group. Once we obtained the first recording, we videoed the next potential subject of the same sex/age class, and so on, until we could not find any other individuals from this age-sex class, in which case we videoed the members of the next age-sex class.

We used the same boat (L568 cm / W135 cm / H38 cm above water) until May, when we replaced it with a boat of similar size (L554 cm / W137 cm / H40 cm above water) and with the same engine model (25HP Yamaha four-stroke engine; grey color). At this point, a second researcher was in the boat (to collect fecal and plant samples for another study). We used the second boat for four of the fast-close approaches, two of the slowclose approaches, and four of the slow-far approaches. For the experiment, we made sure that no potential interference (e.g., fisher boat passing by) was present. During recording sessions for the observational study, a small fishing boat passed by an estimated five times. The boat driver was unfamiliar with the research hypothesis and all team members wore dark clothes so as not to draw attention and were as quiet as possible.

\section{Behavioral Coding}

For the experiment, we recorded the time spent in stress-related behaviors by each subject 3 minutes before the boat approached and for the next 3 minutes once the boat started approaching the subject. Indicators of stress consisted of direct gaze towards the boat, moving backwards, hiding behind leaves, and repeated scratching. We also calculated the total duration of feeding, allogrooming, and aggression during these time periods (Table I).

For the observational study, we coded the total duration of 10 mutually exclusive behaviors that occurred as part of social interactions with other group members (aggression toward others, allogrooming, infant care, sexual behavior, and social play) and in a solitary setting (feeding, resting, moving, autogrooming, and solitary play; Table I) (Boonratana, 1993; Leasor \& Macgregor, 2014). In addition, we coded whether the subjects showed vigilance or were close to other animals in each of the 3-minute recordings. Vigilance was directed at the forest, where other proboscis monkey groups or other animals (e.g., long tailed macaques, Macaca fascicularis) could have been. It included direct gaze toward such groups, which was sometimes accompanied by an alert (sudden pause in behavior) or threatening display (branch shaking and open-mouth facial display). We recorded close proximity when the subjects were within $2 \mathrm{~m}$ of a group member. This did not include proximity with infants when coding adult female behavior, as we assumed that mothers would be close to their infants.

One main coder coded the behaviors with an accuracy of $1 \mathrm{~s}$ by using VLC media player (VideoLAN, Paris, France). The main coder conducted intracoder reliability tests based on 35-39 recordings per behavior (Cohen's kappa $=0.82$ ), vigilance and other stress-related behaviors (0.74), and close proximity (0.96). 
Table I Ten mutually exclusive behaviors contributing to the activity pattern of proboscis monkeys in the riparian area of the Lower Kinabatangan Wildlife Sanctuary, Sabah, Malaysia (from February to July 2015)

\begin{tabular}{ll}
\hline Behaviors & Definitions \\
\hline Resting & Sitting motionless and lying down \\
Feeding & Consuming food and reaching out for leaves to feed on \\
Moving & Walking on hands and legs as well as jumping \\
Allogrooming & Grooming a group member by examing and picking at fur \\
Social play & Playfully interacting with a group member, e.g., playfully hitting \\
Solitary play & Playful behaviors not targeted toward anyone, e.g., swinging without travelling \\
Sexual behavior & Mounting and copulating \\
Autogrooming & Grooming oneself by examing and picking at fur \\
Aggression & Threatening posture, often with high-pitched calls and directed open-mouth displays \\
Infant care & Examining infant and positioning it for suckling \\
\hline
\end{tabular}

\section{Statistical Approach}

We calculated the percentage of each coded behavior for each subject by dividing the total amount of time a subject displayed a behavior by the total visible recoding time for the subject, multiplied by 100 . To test whether an approaching boat affected the proboscis monkeys, we used one-tailed exact Wilcoxon signed-ranks tests to compare the percentage of time that each subject spent showing stress-related behaviors, feeding, allogrooming, and aggression before and after the boat started approaching. For each condition, we compared these behaviors across the two time periods. Where we found significant differences, we used post-hoc, two-tailed, exact Mann-Whitney $U$ tests to compare the behaviors across the sexes.

To describe the subjects' activity, we calculated the mean duration of each behavior coded first for each age-sex class, then for all subjects together. We used two-tailed exact Mann-Whitney $U$ tests to compare alpha males with adult females, adult females with subadult females, and mature subjects (alpha males, adult females, and subadult females) with immature subjects (juveniles and infants) for the duration of vigilance, close social proximity, allogrooming, aggression, and play. We used post-hoc tests to compare females across the groups (two-tailed exact Kruskal-Wallis $\mathrm{H}$ test) and to compare adult and subadult females (two-tailed exact Mann-Whitney $U$ test).

We applied Hommel-Hochberg corrections to adjust $\alpha$ levels for repeated comparisons (Hochbeg \& Hommel, 1998).

\section{Results}

\section{Experiment}

In the experiment, alpha males and adult females showed stress-related behaviors for significantly longer after the boat started approaching them than before the boat approach for two conditions: the fast-close condition and the slow-close 
condition (Fig. 1; Table II). Males and females showed no significant differences in stress-related behaviors after the boat approached (Table II). For the slowfar condition, the subjects showed no difference in the duration of stress-related behaviors after the boat started approaching than before its approach (Fig. 1; Table II).

In addition, the subjects fed for significantly less time after the boat started approaching them than before the boat approached in the fast-close condition (Fig. 2; Table II). Post-hoc tests showed no significant differences between the sexes in feeding after the boat started approaching (Table II). The subjects showed no significant difference in feeding before and after the boat started approaching in the slow-close condition and the slow-far condition (Fig. 2; Table II). Allogrooming and aggression were absent throughout the experiment.

\section{Observational study}

The most common behaviors were resting and then feeding, followed by moving and allogrooming (Table III). Infants spent approximately $40 \%$ of their time playing (Table III). Comparisons between alpha males and adult females showed differences in two of the behaviors studied (Fig. 3). Alpha males spent significantly more time vigilant than adult females (two-tailed exact Mann-Whitney $U$ test with Hommel-Hochberg corrections: $N=31$ females +5 males, $\mathrm{U}=30.00$, $p=0.024$ ). Alpha males also spent significantly more time than females within 2

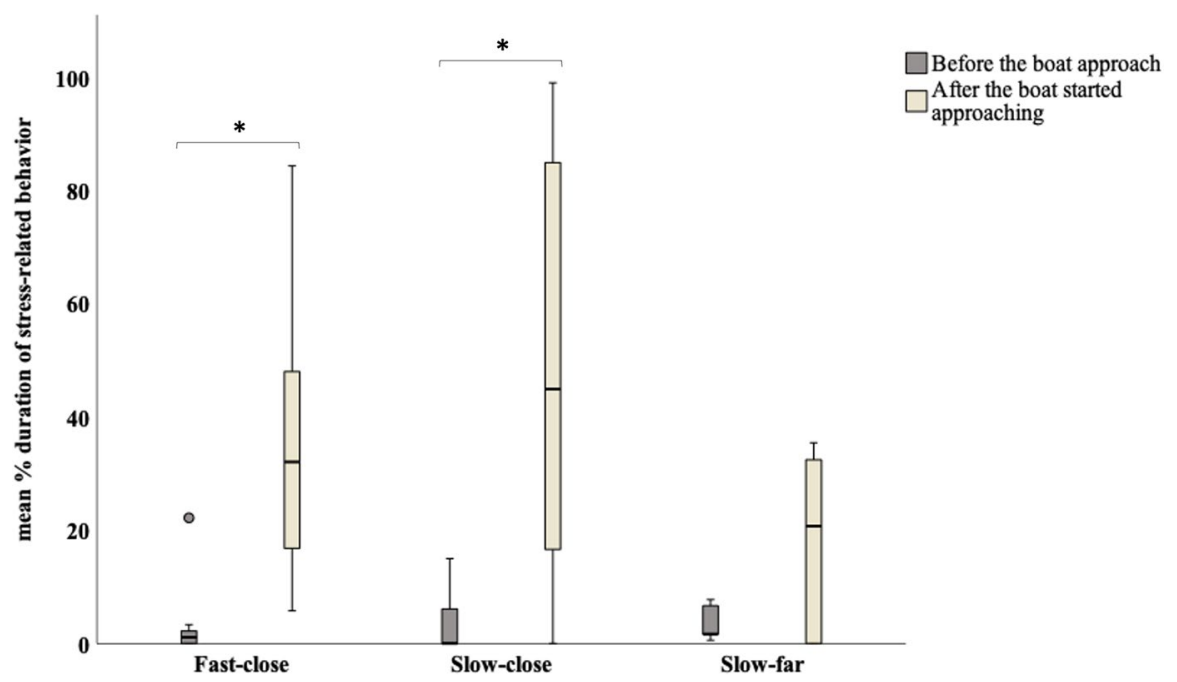

Fig. 1 Effects of an approaching boat on stress-related behaviors in proboscis monkeys in the Lower Kinabatangan Wildlife Sanctuary, Sabah, Malaysia, using three conditions (from February to July 2015). The duration of stress-related behaviors expressed as a percentage of the subjects $(\mathrm{N}=8$, 8 and 7) is shown before and after the boat started approaching. Thick horizontal lines show medians, box lengths show upper and lower quartiles, and thin horizontal lines show the range. A statistically significant difference is shown by an asterisk and horizontal bar. 
Table II Results of statistical tests comparing the response of proboscis monkeys in the riparian area of the Lower Kinabatangan Wildlife Sanctuary, Sabah, Malaysia to an approaching boat, using three conditions (from February to July 2015)

\begin{tabular}{|c|c|c|c|c|c|c|c|}
\hline \multirow[t]{2}{*}{ Conditions } & \multirow[t]{2}{*}{ Behaviors } & \multicolumn{4}{|c|}{ Main analysis } & \multicolumn{2}{|c|}{$\begin{array}{l}\text { Post-hoc } \\
\text { analysis }\end{array}$} \\
\hline & & $\mathrm{N}$ & $\mathrm{Z}$ & $\mathrm{T}$ & $p$ & $\mathrm{U}$ & $p$ \\
\hline Fast-close & Stress-related & 8 & -2.37 & 1 & 0.008 & 5.00 & 0.500 \\
\hline Fast-close & Feeding & 8 & -2.02 & 0 & 0.031 & 7.00 & 0.895 \\
\hline Slow-close & Stress-related & 8 & -2.20 & 0 & 0.016 & 6.50 & 0.875 \\
\hline Slow-close & Feeding & 8 & -1.75 & 0 & 0.063 & & \\
\hline Slow-far & Stress-related & 7 & -1.58 & 1 & 0.078 & & \\
\hline Slow-far & Feeding & 7 & -0.54 & 1 & 0.375 & & \\
\hline
\end{tabular}

We used one-tailed exact Wilcoxon signed-ranks to compare behaviors before and after the boat started approaching. If we found significant differences in the main analysis, we used post hoc MannWhitney $U$ tests to compare behaviors between males $(N=3)$ and females $(N=5)$. We applied Hommel-Hochberg corrections to adjust $\alpha$-levels for all tests.

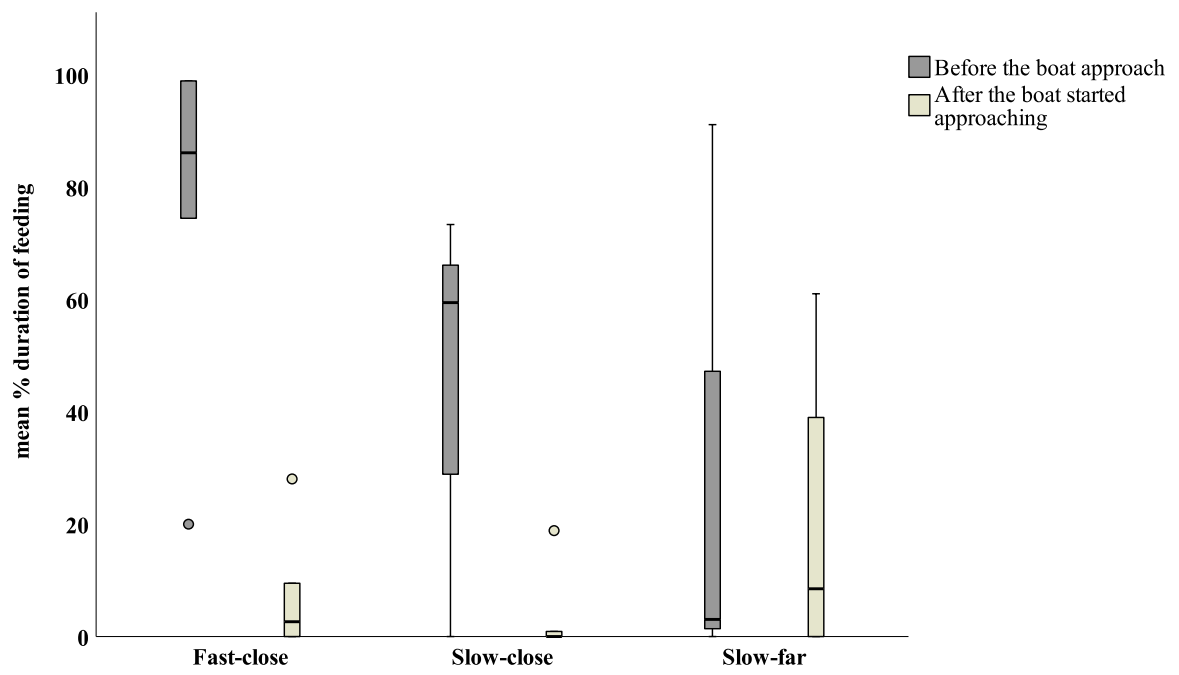

Fig. 2 Effects of an approaching boat on feeding in proboscis monkeys in the Lower Kinabatangan Wildlife Sanctuary, Sabah, Malaysia, using three conditions (from February to July 2015). The duration of feeding expressed as a percentage of the subjects $(\mathrm{N}=8,8$ and 7$)$ is shown before and after the boat started approaching. Thick horizontal lines show medians, box lengths show upper and lower quartiles, and thin horizontal lines show the range. A statistically significant difference is shown by an asterisk and horizontal bar.

$\mathrm{m}$ of other group members $(\mathrm{U}=19.50, p=0.036)$. However, we found no differences between alpha males and adult females for allogrooming $(\mathrm{U}=62.50, p=$ 0.564 ) or aggression ( $\mathrm{U}=62.00, p=0.278$ ). We observed aggression only four times, and all instances the actor was the same alpha male.

Due to the sex class differences in vigilance and close social proximity, we compared the adult females across the six groups, and found no differences across 
Table III Activity patterns of proboscis monkeys living in six one-male multi-female groups of in the riparian area (mornings and evenings combined) of Lower Kinabatangan Wildlife Sanctuary, Sabah, Malaysia (from February to July 2015)

\begin{tabular}{|c|c|c|c|c|c|c|}
\hline & All subjects & Alpha males & Adult females & Subadult females & Juveniles & Infants \\
\hline $\mathrm{N}$ & 87 & 5 & 31 & 20 & 18 & 12 \\
\hline \multirow[t]{2}{*}{ Resting } & 37.9 & 42.5 & 42.4 & 31.8 & 37.3 & 35.7 \\
\hline & $(4.0)$ & (6.4) & $(6.2)$ & (7.3) & $(9.3)$ & (8.6) \\
\hline \multirow[t]{2}{*}{ Feeding } & 33.2 & 37.9 & 41.8 & 40.1 & 30.4 & 15.8 \\
\hline & $(6.5)$ & $(12.8)$ & (11.5) & $(14.3)$ & $(11.5)$ & $(8.6)$ \\
\hline \multirow[t]{2}{*}{ Moving } & 8.7 & 4.6 & 5.0 & 21.4 & 4.7 & 7.6 \\
\hline & (2.6) & $(1.2)$ & $(1.0)$ & (12.9) & (1.3) & $(4.0)$ \\
\hline \multirow[t]{2}{*}{ Allogrooming } & 7.0 & 0.0 & 10.7 & 5.9 & 18.5 & 0.0 \\
\hline & (3.3) & $(0.0)$ & $(5.2)$ & (4.4) & $(9.7)$ & $(6.4)$ \\
\hline \multirow[t]{2}{*}{ Social play } & 6.7 & 0.0 & 0.0 & 0.0 & 7.5 & 26.2 \\
\hline & (1.5) & $(0.0)$ & $(0.0)$ & $(0.0)$ & $(4.5)$ & (12.8) \\
\hline \multirow[t]{2}{*}{ Solitary play } & 3.3 & 0.0 & 0.0 & 0.0 & 1.6 & 14.7 \\
\hline & $(1.1)$ & $(0.0)$ & $(0.0)$ & $(0.0)$ & $(2.0)$ & $(10.9)$ \\
\hline \multirow[t]{2}{*}{ Sexual behavior } & 2.0 & 9.8 & 0.0 & 0.0 & 0.0 & 0.0 \\
\hline & $(0.8)$ & (9.8) & $(0.0)$ & $(0.0)$ & $(0.0)$ & $(0.0)$ \\
\hline \multirow[t]{2}{*}{ Autogrooming } & 0.8 & 3.9 & 0.0 & 0.2 & 0.0 & 0.0 \\
\hline & $(0.3)$ & (3.9) & $(0.0)$ & $(0.2)$ & $(0.0)$ & $(0.0)$ \\
\hline \multirow[t]{2}{*}{ Aggression } & 0.4 & 1.3 & 0.0 & 0.6 & 0.0 & 0.0 \\
\hline & $(0.2)$ & (1.3) & $(0.0)$ & $(0.6)$ & $(0.1)$ & $(0.0)$ \\
\hline \multirow[t]{2}{*}{ Infant care } & 0.0 & 0.0 & 0.1 & 0.0 & 0.0 & 0.0 \\
\hline & $(0.0)$ & $(0.0)$ & $(0.1)$ & $(0.0)$ & $(0.0)$ & $(0.0)$ \\
\hline
\end{tabular}

Data are mean and (SE) duration of each behavior expressed as a percentage of the focal sample

groups for vigilance (two-tailed exact Kruskal-Wallis $\mathrm{H}$ test with Hommel-Hochberg corrections; vigilance: $N=31$ females, $\left.\chi^{2}(5)=6.520, p=0.259\right)$ and social proximity $\left(\chi^{2}(5)=2.221, p=0.695\right)$. We also found no differences between adult females and subadult females in vigilance (two-tailed exact Mann-Whitney $U$ test with Hommel-Hochberg corrections: $N=31$ adult females +20 subadult females, $\mathrm{U}=272.00, p=0.463)$ and proximity $(\mathrm{U}=126.50, p=0.109)$ (Fig. 3).

Comparisons between mature and immature subjects revealed differences in two behaviors (Fig. 4). Immature subjects spent significantly more time playing than mature subjects (two-tailed exact Mann-Whitney $U$ test with HommelHochberg corrections: $N=56$ mature +31 immatures, $\mathrm{U}=459.00, p<0.001$ ). Post-hoc tests revealed that infants played significantly more than juveniles $(N$ $=19$ juveniles +12 infants, $\mathrm{U}=70.00, p=0.046)$. We did not observe any play (social or solitary) in any of the adults and subadults. Furthermore, mature subjects spent significantly more time vigilant compared with immature subjects (two-tailed exact Mann-Whitney $U$ test with Hommel-Hochberg corrections: $N$ $=56$ mature +31 immatures, $\mathrm{U}=644.00, p=0.041)$. We found no significant difference between mature and immature subjects in proximity $(\mathrm{U}=514.50, p=$ 


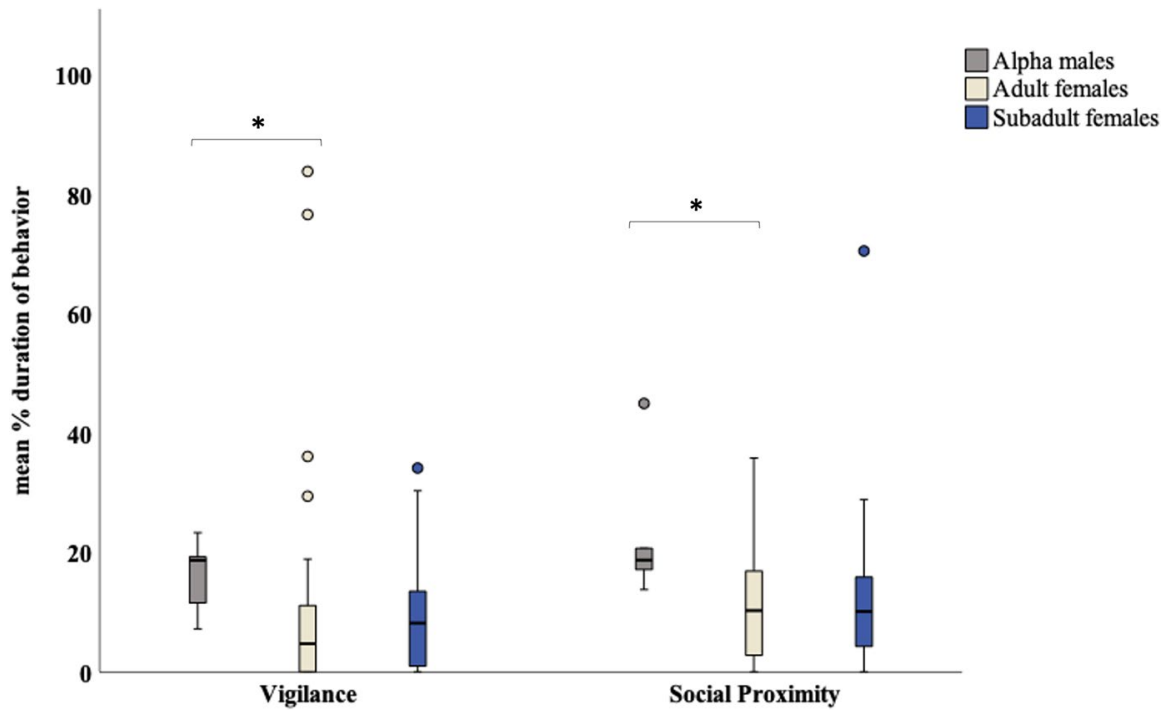

Fig. 3 Comparisons of behavior in mature male and female proboscis monkeys in the Lower Kinabatangan Wildlife Sanctuary, Sabah, Malaysia (from February to July 2015). The duration of vigilance and close social proximity expressed as a percentage of the focal sample is shown for alpha males $(N=5)$, adult females $(N=31)$ and subadult females $(N=20)$. Thick horizontal lines show medians, box lengths show upper and lower quartiles, and thin horizontal lines show the range. A statistically significant difference is shown by an asterisk and horizontal bar.

0.429 ) or allogrooming ( $\mathrm{U}=848.00, p=0.807)$; we did not test aggression due to its occurrence in only one alpha male.

\section{Discussion}

The results of our experiment revealed that proboscis monkeys showed stress-related behaviors for longer after the motor boat started the fast approach to the river bank where they were located compared with their behavior before the approach. We found this impact when the boat travelled for $10 \mathrm{~s}$ and $40 \mathrm{~m}$ (fast-close condition) and for $40 \mathrm{~s}$ and $40 \mathrm{~m}$ (slow-close condition). The monkeys also reduced feeding as a result of the boat approaching in the fast-close condition. The loud engine noise of the motor boat may have contributed to this impact, particularly as loud noise may negatively affect wildlife (Shannon et al., 2016). In our observational study, we found that male proboscis monkeys were more vigilant than females.

Once the boat started to approach the proboscis monkeys, they gazed at the boat for longer than before the boat approach, showed repeated scratching, and often moved quickly backwards to hide in the trees. We did not observe the monkeys fleeing, perhaps because we used a fast condition that we thought would not disturb them enough to leave the riparian area and travel deeper into the forest. At popular riparian sites, however, ecotourist visits with multiple boats may cause proboscis 


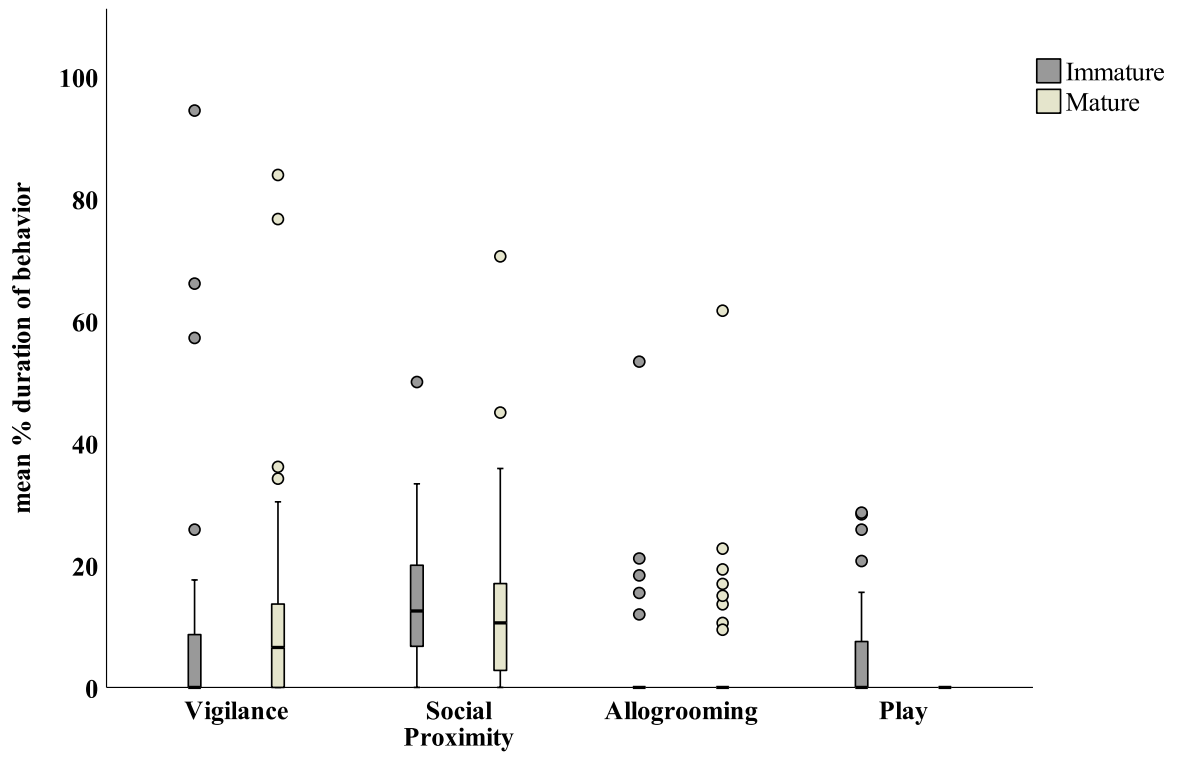

Fig. 4 Comparisons of behavior in mature and immature proboscis monkeys in the Lower Kinabatangan Wildlife Sanctuary, Sabah, Malaysia (from February to July 2015). The duration of vigilance, close social proximity, and play expressed as a percentage of the focal sample is shown for mature (adults and subadults: $N=56$ ) and immature (juveniles and infants: $N=31$ ) monkeys. Thick horizontal lines show medians, box lengths show upper and lower quartiles, and thin horizontal lines show the range. A statistically significant difference is shown by an asterisk and horizontal bar.

monkeys to flee into the forest, where they may then stay to sleep, leading to higher predation risk (Salter et al., 1985; Thiry et al., 2016; Yeager, 1989).

The monkeys showed stress-related behaviors for longer once the boat approached than before it happened, even when the boat approached four times more slowly than in the fast-close condition $(1 \mathrm{~m} / \mathrm{s}$ vs. $4 \mathrm{~m} / \mathrm{s})$. Collectively, our findings suggest that the approach of a single motor boat induces stress in proboscis monkeys when approaching them as closely as $60 \mathrm{~m}$ from the other side of the river, regardless of the speed of approach. The findings match those obtained in studies on sea mammals and birds (Arcangeli et al., 2009; Christiansen et al., 2010; Haysmith \& Hunt, 1995; Stensland \& Berggren, 2007), suggesting that stress is a universal response across animals when a boat approaches - a large, loud, and artificial object moving toward them is likely to be threatening. Future research on the impact of boats on other primates is clearly needed.

The proboscis monkeys also reduced feeding when the motor boat approached them fast and relatively closely (fast-close condition). Feeding was the most common activity of the monkeys in this study, in line with previous research on this species (Boonratana, 1993; Leasor \& Macgregor, 2014) and other folivorous primates (Hladik, 1978). With their specialized folivorous digestive system, proboscis monkeys rely on the trees along river banks and require a long period of resting for digestion (Agoramoorthy et al., 2004; Atmoko et al., 2020; Matsuda, Abram, et al., 2020a; Matsuda et al., 2009a; Yeager, 1989), so that frequent tourist visits via motor 
boats throughout the day are likely to affect the behaviors of wild proboscis monkeys. This study, however, provides limited information on the impact of boats on less common activities, such as allogrooming and aggression, which require a larger sample size.

Our study provides evidence that a single motor boat, with calmly behaving humans in it, may negatively affect primates. We therefore argue that proboscis monkeys, specifically, and perhaps primates in the riparian area, in general, are strongly affected by ecotourism. The presence and behaviors of unfamiliar humans by themselves can induce stress in wild and captive primates and affect their behaviors negatively (Hayward \& Hayward, 2009; Hosey, 2000, 2005; Maréchal et al., 2011; Mitchell et al., 1992; Treves \& Brandon, 2005). Furthermore, four boats have more of an impact than a single boat on agonistic behaviors in proboscis monkeys (Leasor \& Macgregor, 2014). Motor boats are predominantly used in riparian areas for ecotourism, with tourists who are likely unfamiliar to the primates, and their visits may affect the primates (McKinney, 2018; McKinney et al., 2015).

Although our experiment revealed no behavioral differences between the sexes, we did find such differences between age-sex classes in our observational study. Males were more vigilant than the females. It was difficult to determine what initiated these behaviors in the males, mostly due to visibility issues. However, outside the study, we occasionally observed that males directed their gaze (sometimes with alert and threat behaviors) toward other groups of proboscis monkeys (including bachelor groups). Alpha males also respond to other species, including macaques, langurs, crocodiles, and snakes, and potentially clouded leopards (Matsuda et al., 2008). As in other primates (Baldellou \& Henzi, 1992; Gould et al., 1997; Rose \& Fedigan, 1995), vigilance in proboscis monkey males is likely to serve two important functions: to detect male conspecifics with whom they may need to compete for females, and to protect the group members and themselves from potential predators.

The adult and subadult female proboscis monkeys in this study also regularly showed vigilance behaviors. More than half of the mature proboscis monkeys spent $5 \%$ or more of their time vigilant (Fig. 4), and we found no difference in stressrelated behaviors between the adult females and males in our semiexperiment. Juveniles and infants, who are most likely protected by their mothers and the alpha male, spent less time vigilant. While vigilance seems to be an important behavior in the mature proboscis monkeys that we studied, it almost never led to aggression or flight. These relationships are, however, difficult to examine in primates, because vigilance has multiple functions and the difficulty increases when aggression and flight are rare (Caine \& Marra, 1988; Stojan-Dolar \& Heymann, 2010). Indeed, aggression was one of the least common behaviors in this study; only four aggressive instances were reported-all for a single alpha male, consistent with low rates of aggression in other studies of proboscis monkeys (Boonratana, 1993; Hoff et al., 1982; Leasor \& Macgregor, 2014; Sha et al., 2013). Even our boat approaches did not lead to aggressive behaviors. This is in line with other Asian colobines, which typically exhibit high levels of tolerance for others rather than showing aggression (Dasilva, 1992; Fashing, 2001; Huang et al., 2003; Matsuda et al., 2009b; Md-Zain \& Ch'ng, 2011; Wasserman \& Chapman, 2003). 
Interestingly, adult females spent less time close to other group members than alpha males did. Furthermore, mature females directed affiliative behaviors in form of allogrooming towards their presumed offspring and other mature females but not toward the males - a pattern that matches previous findings for proboscis monkeys (Yeager, 1990) and other primates living in one-male, multifemale groups (Silk et al., 2006; Swedell, 2002; Wei et al., 2012). Although proboscis monkeys live in stable groups (Yeager, 1991) and males may form long-lasting strong bonds with females in primates living in one-male, multifemale groups (Haunhorst et al., 2016), we find it difficult to explain why alpha males spent more time close to group members than the adult females. More research is needed to examine the social networks of males and females in proboscis monkey groups, especially because their social relationships are likely to be complex not only across individuals within the same group but also across nearby groups (Matsuda, Tuuga, et al., 2012), with multiple groups making up a larger social environment (Grueter \& van Schaik, 2010).

Methodological limitations also may explain our results for proximity. Perhaps due to their sentinel role, males may have positioned themselves at the canopy periphery, where nearby group members are more exposed and visible to the researchers. However, the nonvisibility scores obtained within a 2-m radius of the subjects (i.e., the distance used to test for social proximity) were almost identical across males and females (mean $32.9 \%$ in both sexes), making this explanation unlikely.

Data on playful behaviors showed gradual changes along the ontogenetic trajectory in the proboscis monkeys. This finding is consistent with the notion that social and solitary play represent an important platform for the development of social, cognitive, emotional, and motoric resources (Bekoff \& Allen, 2002; Fredrickson, 2001; Gervais \& Wilson, 2005). Infants played even more often than the juveniles, whereas mature proboscis monkeys showed no playful behaviors. Immature primates regularly play on their own and with their peers, often while surrounded by their mothers (Davila-Ross et al., 2011; Palagi, 2018; van Leeuwen et al., 2011).

We focused on the mornings and evenings when the proboscis monkey groups were visible in the riparian area. It seems likely that when the monkeys are deeper in the forest during the day, some of their behaviors might differ due to the higher exposure to predators (Matsuda et al., 2008;Salter et al., 1985 ; Thiry et al., 2016 ; Yeager, 1989). Specifically vigilance, close proximity, and aggression might increase (Baldellou \& Henzi, 1992; Matsuda et al., 2008; Rose \& Fedigan, 1995). These behaviors also might be affected by environmental conditions, where predation threats are reduced by high water levels on flooded days, allowing proboscis monkeys to extend their sleeping sites deeper into the forest (Matsuda et al., 2010). On such occasions, the degree of association between groups is lower compared with nonflooded days when the monkeys sleep closer to each other (Matsuda et al., 2010; Murai, 2004). We suggest that future research examines the circadian pattern of behavior and compares behavior across habitat types and seasons, factors that influence behavior in other rainforest-living primates (Davila Ross \& Geissmann, 2009; King \& Cowlishaw, 2009; Ostner et al., 2002).

Motor-boat travel becomes particularly problematic when it involves multiple loud tourist boats, potentially causing the monkeys to leave their safe sleeping sites and 
to flee deep into the forest as it gets dark, where they could be faced with higher risk of predation (Salter et al., 1985; Thiry et al., 2016; Yeager, 1989). Collectively, this study and previous work (Leasor \& Macgregor, 2014) suggest that tourism in riparian areas, which is largely unregulated (Goossens et al., 2003; Sha et al., 2008), may affect the proboscis monkeys' health and safety, and that specifically, empirically grounded guidelines are needed (Sha et al., 2011). Our study highlights the importance of keeping a distance from proboscis monkeys and perhaps also other primates in the riparian area when in motorboats, and preferably approaching them similarly as in the slow-far condition, where we observed no impact. For the slow-far condition, we approached the monkeys for $20 \mathrm{~s}$ at a speed of $3.6 \mathrm{~km} / \mathrm{hr}$ when $100 \mathrm{~m}$ or further away. Thus, guidelines for primate tourism in the riparian areas should include an approach speed of no more than $4 \mathrm{~km} / \mathrm{hr}$ within $100 \mathrm{~m}$ of the proboscis monkeys. It also is important to keep a distance from the monkeys, preferably no closer than $60 \mathrm{~m}$ away from the monkeys (based on the impact of the slow-close condition, where we travelled for $40 \mathrm{~m}$ ). Such information might be helpful for tourists, allowing them to modify their behaviors when visiting the primates and when encouraging guides to follow the guidelines. Further empirical, policy-focused research is needed to better understand the impact of tourists and boats on proboscis monkeys and other primates (Vanlangendonck et al., 2015), preferably including additional noninvasive measures of stress-related states, such as hormonal analysis (Sheriff et al., 2011), to help make ecotourism on these monkeys more sustainable (Buckley, 2011; Moorhouse et al., 2015).

Acknowledgments Special thanks go to Professor Elke Zimmermann, who was a wonderful mentor to MDR throughout the years and who inspired this study as well as other field research in Borneo during their visit at Danau Girang Field Centre. We would also like to thank Ute Radespiel, Ikki Matsuda, and Joanna Setchell as well as two unknown reviewers for their very helpful comments regarding earlier versions of this manuscript as well as Alan Costall for his advice throughout this project, K. Schoerk and R. Scarsbrook for their assistance, and the staff and volunteers of Danau Girang Field Centre for their help during the data collection. The field study was part funded by the Act for Wildlife Research grant from Chester Zoo, Sime Darby Foundation and The Margot Marsh Biodiversity Foundation (PR12-012 \& PR14-36). This work was reviewed and approved by The University of Portsmouth Animal Welfare and Ethical Review Board, reference number 215A. Danau Girang Field Centre and the Sabah Wildlife Department gave permission for research to take place in the area. The research adhered to the legal requirements of Borneo, Malaysia and was approved by the Sabah Biodiversity Centre, access license number: JKM/MBS.1000-2/2 (365).

Author Contributions MDR, HP, BG, and DJS designed the study. HP, DJS and SKSSN contributed to the data collection. VG, MDR, and HP handled and analysed the data. MDR and HP wrote the manuscript, and VG, BG, and DJS further contributed to it.

Funding This study was funded by the Act for Wildlife Research grant from Chester Zoo, Sime Darby Foundation and The Margot Marsh Biodiversity Foundation (PR12-012 \& PR14-36).

Open Access This article is licensed under a Creative Commons Attribution 4.0 International License, which permits use, sharing, adaptation, distribution and reproduction in any medium or format, as long as you give appropriate credit to the original author(s) and the source, provide a link to the Creative Commons licence, and indicate if changes were made. The images or other third party material in this article are included in the article's Creative Commons licence, unless indicated otherwise in a credit line to the material. If material is not included in the article's Creative Commons licence and your intended use is not permitted by statutory regulation or exceeds the permitted use, you will need to obtain permission directly from the copyright holder. To view a copy of this licence, visit http://creativecommons.org/licen ses/by/4.0/. 


\section{References}

Agoramoorthy, G., Alagappasamy, C., \& Hsu, M. J. (2004). Can proboscis monkeys be successfully maintained in captivity? A case of swings and roundabouts. Zoo Biology, 23(6), 533-544.

Alberts, S., Hollister-Smith, J., Mututua, R., Sayialel, S., Muruthi, P. M., Warutere, J. K., \& Altmann, J. (2005). Seasonality in primates: studies of living and extinct human and non-human primates. In D. K. Brockman \& C. P. van Schaik (Eds.), Seasonality and long-term change in a savannah environment (pp. 157-196). Cambridge University Press.

Altmann, J. (1974). Observational Study of Behavior: Sampling Methods. Behaviour, 49(3/4), 227-267.

Arcangeli, A., \& Crosti, R., del Leviatano, A., \& Rome, I (2009). The short-term impact of dolphinwatching on the behaviour of bottlenose dolphins (Tursiops truncatus) in western Australia. Journal of Marine Animals and Their Ecology, 2(1), 3-9.

Arnold, K., \& Whiten, A. (2003). Grooming interactions among the chimpanzees of the Budongo Forest, Uganda: tests of five explanatory models. Behaviour, 140(4), 519-552.

Atmoko, T., Mardiastuti, A., Bismark, M., Prasetyo, L. B., \& Iskandar, E. (2020). Habitat suitability of proboscis monkey (Nasalis larvatus) in Berau Delta, East Kalimantan, Indonesia. Biodiversitas Journal of Biological Diversity, 21(11), 5155-5163.

Baldellou, M., \& Henzi, S. P. (1992). Vigilance, predator detection and the presence of supernumerary males in vervet monkey troops. Animal Behaviour, 43(3), 451-461.

Baş, A. A., Christiansen, F., Öztürk, B., Öztürk, A. A., Erdoğan, M., \& Watson, L. (2017). Marine vessels alter the behaviour of bottlenose dolphins Tursiops truncatus in the Istanbul Strait, Turkey. Endangered Species Research, 34, 1-14.

Behie, A. M., Pavelka, M. S., \& Chapman, C. A. (2010). Sources of variation in fecal cortisol levels in howler monkeys in Belize. American Journal of Primatology, 72, 600-606.

Bekoff, M., \& Allen, C. (2002). The evolution of social play: Interdisciplinary analyses of cognitive processes. In M. Bekoff, C. Allen, \& G. M. Burghardt (Eds.), The cognitive animal (pp. 429-435). The MIT Press.

Benchimol, M., \& Venticinque, E. M. (2014). Responses of Primates to Landscape Change in Amazonian Land-bridge islands - a Multi-scale Analysis. Biotropica, 46, 470-478.

Bennett, E. L., \& Sebastian, A. C. (1988). Social organization and ecology of proboscis monkeys (Nasalis larvatus) in mixed coastal forest in Sarawak. International Journal of Primatology, 9(3), 233-255.

Bigoni, F., Stanyon, R., Wimmer, R., \& Schempp, W. (2003). Chromosome painting shows that the proboscis monkey (Nasalis larvatus) has a derived karyotype and is phylogenetically nested within Asian Colobines. American Journal of Primatology, 60(3), 85-93.

Birke, L. (2002). Effects of browse, human visitors and noise on the behavior of captive orangutans. Animal Welfare, 11(2), 189-202.

Boonratana, R. (1993). The ecology and behavior of the proboscis monkey (Nasalis larvatus) in the Lower Kinabatangan, Sabah. Mahidol University (unpublished doctoral dissertation).

Boonratana, R. (2000). A short note on vigilance exhibited by proboscis monkeys (Nasalis larvatus) in the Lower Kinabatangan, Sabah, Malaysia. Tigerpaper, 27(4), 21-22.

Buckley, R. (2011). Tourism and environment. Annual Review of Environment and Resources, 36(1), 397-416.

Caine, N. G., \& Marra, S. L. (1988). Vigilance and social organization in two species of primates. Animal Behaviour, 36(3), 897-904.

Chamove, A. S., Hosey, G. R., \& Schaetzel, P. (1988). Visitors excite primates in zoos. Zoo Biology, 7(4), 359-369.

Chapman, C. A., Gillespie, T. R., \& Goldberg, T. L. (2005). Primates and the ecology of their infectious diseases: how will anthropogenic change affect host-parasite interactions? Evolutionary Anthropology, 14(4), 134-144.

Cheney, D. L., \& Seyfarth, R. M. (1977). Behavior of adult and immature male baboons during intergroup encounters. Nature, 269(5627), 404-406.

Christiansen, F., Lusseau, D., Stensland, E., \& Berggren, P. (2010). Effects of tourist boats on the behaviour of Indo-Pacific bottlenose dolphins off the south coast of Zanzibar. Endangered Species Research, 11(1), 91-99.

Constantine, R. (1999). Effects of tourism on marine mammals in New Zealand. Science For Conservation, 106, Department of Conservation.

Darwin, C. (1871). The descent of man, and selection in relation to sex. John Murray. 
Dasilva, G. (1992). The Western Black-And-White Colobus as a Low-Energy Strategist: Activity Budgets, Energy Expenditure and Energy Intake. Journal of Animal Ecology, 61(1), 79-91.

Davila Ross, M., \& Geissmann, T. (2009). Circadian long call distribution in wild orangutans. Revue de Primatologie, 1, 2-9.

Davila-Ross, M., Allcock, B., Thomas, C., \& Bard, K. A. (2011). Aping expressions? Chimpanzees produce distinct laugh types when responding to laughter of others. Emotion, 11(5), 1013-1020.

de la Torre, S., Snowdon, C. T., \& Bejarano, M. (2000). Effects of human activities on wild pygmy marmosets in Ecuadorian Amazonia. Biological Conservation, 94(2), 153-163.

Fan, P., \& Xiang, Z. (2013). Ecotourism disturbances to non-human primates. Zoological Research, 34(1), 55-58.

Fashing, P. J. (2001). Activity and ranging patterns of guerezas in the Kakamega Forest: intergroup variation and implications for intragroup feeding competition. International Journal of Primatology, 22(4), 549-577.

Fredrickson, B. L. (2001). The role of positive emotions in positive psychology: The broaden-and-build theory of positive emotions. American Psychologist, 56(3), 218-226.

Fuentes, A., \& Hockings, K. J. (2010). The ethnoprimatological approach in primatology. American Journal of Primatology, 72, 841-847.

Gervais, M., \& Wilson, D. S. (2005). The evolution and functions of laughter and humor: A synthetic approach. The Quarterly Review of Biology, 80(4), 395-430.

Goossens, B., Setchell, J. M., Abulani, D. M. A., Jalil, F., James, S. S., Aris, S. H., et al (2003). A boat survey of primates in the Lower Kinabatangan Wildlife Sanctuary. In M. Mohamed, A. Takano, B. Goossens, \& R. Indran (Eds.), Lower Kinabatangan Scientific Expedition (pp. 37-90). University of Malaysia.

Gould, L., Fedigan, L. M., \& Rose, L. M. (1997). Why be vigilant? The case of the alpha animal. International Journal of Primatology, 18(3), 401-414.

Grossberg, R., Treves, A., \& Naughton-Treves, L. (2003). The incidental ecotourist: measuring visitor impacts on endangered howler monkeys at a Belizean archaeological site. Environmental Conservation, 30(1), 40-51.

Grueter, C. C., \& van Schaik, C. P. (2010). Evolutionary determinants of modular societies in colobines. Behavioral Ecology, 21(1), 63-71.

Grueter, C. C., Chapais, B., \& Zinner, D. (2012). Evolution of multilevel social systems in nonhuman primates and humans. International Journal of Primatology, 33(5), 1002-1037.

Haunhorst, C. B., Schülke, O., \& Ostner, J. (2016). Opposite-sex social bonding in wild Assamese macaques. American Journal of Primatology, 78(8), 872-882.

Haysmith, L., \& Hunt, J. D. (1995). Nature tourism: impacts and management. In R. L. Knight \& K. L. Gutzwiller (Eds.), Wildlife and recreationists: Coexistence through management and research (pp. 203-220). Island Press.

Hayward, M. W., \& Hayward, G. J. (2009). The impact of tourists on lion Panthera leo behaviour, stress and energetics. Acta Theriologica, 54(3), 219-224.

Hladik, C. M. (1978). Adaptive strategies of primates in relation to leaf eating. In G. G. Montgomery (Ed.), The ecology of arboreal folivores (pp. 373-395). Smithsonian Institution Press.

Hochbeg, Y., \& Hommel, G. (1998). Step-up multiple testing procedures. In: S. Kotz (Ed.), Encyclopedia of statistical sciences (418-422). Supp 2. Wiley

Hoff, M. P., Nadler, R. D., \& Maple, T. L. (1982). Control role of an adult male in a captive group of lowland gorillas. Folia Primatologica, 38(1-2), 72-85.

Hosey, G. R. (2000). Zoo animals and their human audiences: What is the visitor effect? Animal Welfare, 9(4), 343-357.

Hosey, G. R. (2005). How does the zoo environment affect the behaviour of captive primates? Applied Animal Behaviour Science, 90(2), 107-129.

Hsu, M. J., Kao, C. C., \& Agoramoorthy, G. (2009). Interactions between visitors and Formosan macaques (Macaca cyclopis) at Shou-Shan Nature Park, Taiwain. American Journal of Primatology, 71, 214-222.

Huang, C., Wei, F., Li, M., Li, Y., \& Sun, R. (2003). Sleeping cave selection, activity pattern and time budget of white-headed langurs. International Journal of Primatology, 24(4), 813-824.

Huskisson, S. M., Doelling, C. R., Ross, S. R., \& Hopper, L. M. (2021). Assessing the potential impact of zoo visitors on the welfare and cognitive performance of Japanese macaques. Applied Animal Behaviour Science, 243, 105453.

Isbell, L. A., Young, T., \& P. (2002). Ecological models of female social relationships in primates: similarities, disparities, and some directions for future clarity. Behavior, 139(2/3), 177-202. 
Karczmarski, L., Thornton, M., \& Cockroft, V. (1997). Description of selected behaviors of humpback dolphins, Sousa chinensis. Aquatic Mammals, 23(3), 127-134.

King, A. J., \& Cowlishaw, G. (2009). All together now: behavioral synchrony in baboons. Animal Behavior, 78(6), 1381-1387.

Kirkpatrick, R. C., Long, Y. C., Zhong, T., \& Xiao, L. (1998). Social organization and range use in the Yunnan snub-nosed monkey Rhinopithecus bieti. International Journal of Primatology, 19(1), 13-51.

Kitchen, D. M., \& Beehner, J. C. (2007). Factors affecting individual participation in group-level aggression among non-human primates. Behavior, 144(12), 1551-1581.

Leasor, H. C., \& Macgregor, O. J. (2014). Proboscis Monkey Tourism: "Can We Make it Ecotourism”? In A. E. Russon \& J. Wallis (Eds.), Primate Tourism, A Tool for Conservation? (pp. 56-75). Cambridge University Press.

Lee, P. (2010). Sharing space: can ethnoprimatology contribute to the survival of nonhuman primates in human-dominated globalized landscapes? American Journal of Primatology, 72, 925-931.

Lhota, S., Scott, K., \& Sha, J. C. M. (2019). Primates in flooded forests of Borneo. Primates in Flooded Forests of Borneo: Opportunities and Challenges for Ecotourism as a Conservation Strategy (pp. 331-339). Cambridge University Press.

Lovett, J. C., \& Marshall, A. R. (2006). Why should we conserve primates? African Journal of Ecology, 44(2), 113-115.

Maréchal, L., Semple, S., Majolo, B., Qarro, M., Heistermann, M., \& MacLarnon, A. (2011). Impacts of tourism on anxiety and physiological stress levels in wild male Barbary macaques. Biological Conservation, 144(9), 2188-2193.

Matsuda, I., Tuuga, A., \& Higashi, S. (2008). Clouded leopard (Neofelis diardi) predation on proboscis monkeys (Nasalis larvatus) in Sabah, Malaysia. Primates, 49(3), 227-231.

Matsuda, I., Tuuga, A., \& Higashi, S. (2009a). The feeding ecology and activity budget of proboscis monkeys. American Journal of Primatology, 71(6), 478-492.

Matsuda, I., Tuuga, A., \& Higashi, S. (2009b). Ranging behavior of proboscis monkeys in a riverine forest with special reference to ranging in inland forest. International Journal of Primatology, $30(2), 313-325$.

Matsuda, I., Tuuga, A., \& Higashi, S. (2010). Effects of water level on sleeping-site selection and inter - group association in proboscis monkeys: why do they sleep alone inland on flooded days? Ecological Research, 25(2), 475-482.

Matsuda, I., Tuuga, A., Bernard, H., \& Furuichi, T. (2012). Inter-individual relationships in proboscis monkeys: A preliminary comparison with other non-human primates. Primates, 53(1), 13-23.

Matsuda, I., Abram, N. K., Stark, D. J., Sha, J. C. M., Ancrenaz, M., Goossens, B., Lackman, I., Tuuga, A., \& Kubo, T. (2020a). Population dynamics of the proboscis monkey Nasalis larvatus in the Lower Kinabatangan, Sabah, Borneo, Malaysia. Oryx, 54(4), 583-590.

Matsuda, I., Stark, D. J., Saldivar, D. A. R., Tuuga, A., Nathan, S. K. S. S., Goossens, B., van Schaik, C. P., \& Koda, H. (2020b). Large male proboscis monkeys have larger noses but smaller canines. Communications Biology, 3, 522.

Mattson, M. C., Thomas, J. A., \& Aubin, D. S. (2005). Effects of boat activity on the behavior of bottlenose dolphins (Tursiops truncatus) in waters surrounding Hilton Head Island, South Carolina. Aquatic Mammals, 31(1), 133-140.

McKinney, T. (2018). Ecotourism. In W. Trevathan, M. Cartmill, D. L. Dufour, C. S. Larsen, D. O’Rourke, H. K. Rosenberg, \& K. B. Strier (Eds.), The International Encyclopedia of Biological Anthropology (pp. 1-4). John Wiley \& Sons, Inc..

McKinney, T., Westin, J. L., \& Serio-Silva, J. C. (2015). Anthropogenic Habitat Modification, Tourist Interactions and Crop-Raiding in Howler Monkeys. In M. Kowalewski, P. Garber, L. CortésOrtiz, B. Urbani, \& D. Youlatos (Eds.), Howler Monkeys. Developments in Primatology: Progress and Prospects (pp. 281-312). Springer.

Md-Zain, B. M., \& Ch'ng, C. E. (2011). The activity patterns of a group of Cantor's dusky leaf monkeys (Trachypithecus obscurus halonifer). International Journal of Zoological Research, 7(1), 59-67.

Meijaard, E., \& Nijman, V. (2000). Distribution and conservation of the proboscis monkey (Nasalis larvatus) in Kalimantan, Indonesia. Biological Conservation, 92(1), 15-24.

Mitchell, G., Herring, F., Obradovich, S., Tromborg, C., Dowd, B., Neville, L. E., \& Field, L. (1991). Effects of visitors and cage changes on the behaviors of mangabeys. Zoo Biology, 10(5), 417-423.

Mitchell, G., Tromborg, C. T., Kaufman, J., Bargabus, S., Simoni, R., \& Geissler, V. (1992). More on the 'influence' of zoo visitors on the behaviour of captive primates. Applied Animal Behaviour Science, 35(2), 189-198. 
Moorhouse, T. P., Dahlsjö, C. A. L., Baker, S. E., D’Cruze, N. C., \& Macdonald, D. W. (2015). The customer isn't always right - conservation and animal welfare implications of the increasing demand for wildlife tourism. PLOS ONE, 10(10), e0138939.

Muehlenbein, M. P., Martinez, L. A., Lemke, A. A., Ambu, L., Nathan, S., Alsisto, S., \& Sakong, R. (2010). Unhealthy travelers present challenges to sustainable primate ecotourism. Travel Medicine and Infectious Disease, 8, 169-175.

Muehlenbein, M. P., Ancrenaz, M., Sakong, R., Ambu, L., Prall, S., et al (2012). Ape Conservation Physiology: Fecal Glucocorticoid Responses in Wild Pongo pygmaeus morio following Human Visitation. PLOS ONE, 7(3), e33357.

Murai, T. (2004). Social structure and mating behavior of proboscis monkey Nsalis larvatus (Primates; Colobinae) [Dissertation]. Graduate School of Environmental Earth Science, Hokkaido University

O'Leary, H., \& Fa, J. E. (1993). Effects of Tourists on Barbary Macaques at Gibraltar. Folia Primatologica, 61(2), 77-91.

Ostner, J., Kappeler, P. M., \& Heistermann, M. (2002). Seasonal variation and social correlates of androgen excretion in male redfronted lemurs (Eulemur fulvus rufus). Behavioral Ecology and Sociobiology, 52(6), 485-495.

Palagi, E. (2018). Not just for fun! Social play as a springboard for adult social competence in human and non-human primates. Behavioral Ecology and Sociobiology, 72(6), 1-14.

Rawlings, B., Davila-Ross, M., \& Boysen, S. T. (2014). Semi-wild chimpanzees open hard-shelled fruits differently across communities. Animal Cognition, 17(4), 891-899.

Rose, L. M., \& Fedigan, L. M. (1995). Vigilance in white-faced capuchins, Cebus capucinus, in Costa Rica. Animal Behaviour, 49(1), 63-67.

Sackett, D. P., Oswald, M., \& Erwin, J. (1975). Aggression among captive female pigtail monkeys in allfemale and harem groups. Journal of Biological Psychology, 17(2), 17-20.

Salter, R. E., MacKenzie, N. A., Nightingale, N., Aken, K. M., \& Chai, P. K. (1985). Habitat use, ranging, behavior, and food habits of the proboscis monkey, Nasalis larvatus (van Wurmb), Sarawak. Primates, 26(4), 436-451.

Serio-Silva, J. C. (2006). Las Islas de los Changos (the Monkey Islands): the economic impact of ecotourism in the region of Los Tuxtlas, Veracruz, Mexico. American Journal of Primatology, 68(5), 499-506.

Sha, J. C. M., Bernard, H., \& Nathan, S. (2008). Status and conservation of proboscis monkeys (Nasalis larvatus) in Sabah, East Malaysia. Primate Conservation, 23, 107-120.

Sha, J., Matsuda, I., \& Bernard, H. (2011). The natural history of the proboscis monkey. Natural History Publications.

Sha, J. C. M., Alagappasamy, S., Chandran, S., Cho, K. M., \& Guha, B. (2013). Establishment of a captive all-male group of proboscis monkey (Nasalis larvatus) at the Singapore Zoo. Zoo Biology, 32(3), 281-290.

Shannon, G., McKenna, M. F., Angeloni, L. M., Crooks, K. R., Fristrup, K. M., Brown, E., et al (2016). A synthesis of two decades of research documenting the effects of noise on wildlife. Biological Reviews, 91(4), 982-1005.

Sheriff, M. J., Dantzer, B., Delehanty, B., Palme, R., \& Boonstra, R. (2011). Measuring stress in wildlife: techniques for quantifying glucocorticoids. Oecologia, 166(4), 869-887.

Silk, J. B., Alberts, S. C., \& Altmann, J. (2006). Social relationships among adult female baboons (Papio cynocephalus) II. Variation in the quality and stability of social bonds. Behavioral Ecology and Sociobiology, 61(2), 197-204.

Sjahfirdi, L., \& Noviandini, D. (2021). Social and reproductive behaviour of proboscis monkey Nasalis larvatus (van Wurmb, 1787) at Taman Safari Bogor, West Java. Journal of Physics: Conference Series, 2021, 012051.

Stark, D. J., Nijman, V., Lhota, S., Robins, J. G., \& Goossens, B. (2012). Modeling population viability of local proboscis monkey Nasalis larvatus populations: conservation implications. Endangered Species Research, 16(1), 31-43.

Stark, D. J., Vaughan, I. P., Ramirez Saldivar, D. A., Nathan, S. K. S. S., \& Goossens, B. (2017). Evaluating methods for estimating home ranges using GPS collars: a comparison using proboscis monkeys (Nasalis larvatus). PLoS ONE, 12(3), e0174891.

Stensland, E., \& Berggren, P. (2007). Behavioural changes in female Indo-Pacific bottlenose dolphins in response to boat-based tourism. Marine Ecology Progress Series, 332, 225-234.

Stojan-Dolar, M., \& Heymann, E. W. (2010). Vigilance in a cooperatively breeding primate. International Journal of Primatology, 31(1), 95-116.

Swedell, L. (2002). Affiliation among females in wild hamadryas baboons (Papio hamadryas hamadryas). International Journal of Primatology, 23(6), 1205-1226. 
Thiry, V., Stark, D. J., Goossens, B., Slachmuylder, J. L., Vercauteren Drubbel, R., \& Vercauteren, M. (2016). Use and selection of sleeping sites by proboscis monkeys, Nasalis larvatus, along the Kinabatangan River, Sabah, Malaysia. Folia Primatologica, 87(3), 180-196.

Timm, R. M., Lieberman, D., Lieberman, M., \& McClearn, D. (2009). Mammals of Cabo Blanco: history, diversity, and conservation after 45 years of regrowth of a Costa Rican dry forest. Forest Ecology and Management, 258, 997-1013.

Treves, A., \& Brandon, K. (2005). Tourist impacts on the behavior of Black Howling Monkeys (Alouatta pigra) at Lamanai, Belize. In J. D. Paterson \& J. Wallis (Eds.), Commensalism and conflict: The human-primate interface. American Society of Primatologists.

van Leeuwen, E. J. C., Zimmermann, E., \& Davila Ross, M. (2011). Responding to inequities: Gorillas try to maintain their competitive advantage during play fights. Biology Letters, 7(1), 39-42.

Vanlangendonck, N., Nuñez, G., Chaves, A., \& Gutiérrez-Espeleta, G. A. (2015). New route of investigation for understanding the impact of human activities on the physiology of non-human primates. Journal of Primatology, 4(1), 2-8.

Wasserman, M. D., \& Chapman, C. A. (2003). Determinants of colobine monkey abundance: the importance of food energy, protein and fibre content. Journal of Animal Ecology, 72(4), 650-659.

Wei, W., Qi, X. G., Guo, S. T., Zhao, D. P., Zhang, P., Huang, K., \& Bao-Guo, L. (2012). Market powers predict reciprocal grooming in golden snub-nosed monkeys (Rhinopithecus roxellana). PLoS ONE, 7(5), e36802.

Wittig, R. M., Crockford, C., Lehmann, J., Whitten, P. L., Seyfarth, R. M., \& Cheney, D. L. (2008). Focused grooming networks and stress alleviation in wild female baboons. Hormones and Behavior, 54(1), 170-177.

Yeager, C. P. (1989). Feeding ecology of the proboscis monkey (Nasalis larvatus). International Journal of Primatology, 10(6), 497-530.

Yeager, C. P. (1990). Proboscis monkey (Nasalis larvatus) social organization: group structure. American Journal of Primatology, 20(2), 95-106.

Yeager, C. P. (1991). Proboscis monkey (Nasalis larvatus) social organization: intergroup patterns of association. American Journal of Primatology, 23(2), 73-86.

\section{Authors and Affiliations}

\section{Marina Davila-Ross ${ }^{1}$ (D) Helen Pople ${ }^{1} \cdot$ Violet Gibson $^{1}$ (D) Senthilvel K. S. S. Nathan ${ }^{2}$ Benoit Goossens $s^{2,3,4}$ (D) Danica J. Stark ${ }^{3,4,5}$ (i)}

Marina Davila-Ross

Marina.Davila-Ross@port.ac.uk

1 Psychology Department, University of Portsmouth, King Henry Building, King Henry 1st Street, Portsmouth, Hampshire PO1 2DY, UK

2 Sabah Wildlife Department, Wisma Muis, 88100 Kota Kinabalu, Sabah, Malaysia

3 Danau Girang Field Centre, c/o Sabah Wildlife Department, Wisma Muis, 88100 Kota Kinabalu, Sabah, Malaysia

4 Organisms and Environment Division, Cardiff School of Biosciences, Cardiff University, Sir Martin Evans Building, Museum Avenue, Cardiff CF10 3AX, UK

5 Wilder Institute/Calgary Zoo, 1300 Zoo Road, NE, Calgary, AB T2N 0E7, Canada 